\title{
BMJ Open Patient Evaluation of Emotional Comfort Experienced (PEECE): developing and testing a measurement instrument
}

\author{
A M Williams, ${ }^{1,2}$ L Lester, $^{3} \mathrm{C}$ Bulsara, ${ }^{4}$ A Petterson, ${ }^{5} \mathrm{~K}$ Bennett, ${ }^{6} \mathrm{E}$ Allen, ${ }^{1,7}$ \\ D Joske ${ }^{8}$
}

To cite: Williams AM, Lester L, Bulsara C, et al. Patient Evaluation of Emotional Comfort Experienced (PEECE): developing and testing a measurement instrument. BMJ Open 2017;7:e012999. doi:10.1136/bmjopen-2016012999

- Prepublication history for this paper is available online. To view these files please visit the journal online (http://dx.doi.org/10.1136/ bmjopen-2016-012999).

Received 14 June 2016 Revised 19 October 2016 Accepted 14 December 2016

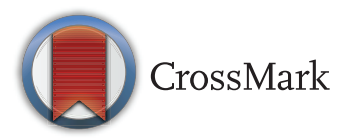

For numbered affiliations see end of article.

\section{Correspondence to} Professor AM Williams; anne.williams@murdoch.edu. $\mathrm{au}$

\section{ABSTRACT}

Objectives: The Patient Evaluation of Emotional Comfort Experienced (PEECE) is a 12-item questionnaire which measures the mental well-being state of emotional comfort in patients. The instrument was developed using previous qualitative work and published literature.

Design: Instrument development.

Setting: Acute Care Public Hospital, Western Australia. Participants: Sample of 374 patients.

Interventions: A multidisciplinary expert panel assessed the face and content validity of the instrument and following a pilot study, the psychometric properties of the instrument were explored.

Main outcome measures: Exploratory and confirmatory factor analysis assessed the underlying dimensions of the PEECE instrument; Cronbach's $\alpha$ was used to determine the reliability; $\kappa$ was used for test-retest reliability of the ordinal items.

Results: 2 factors were identified in the instrument and named 'positive emotions' and 'perceived meaning'. A greater proportion of male patients were found to report positive emotions compared with female patients. The instrument was found to be feasible, reliable and valid for use with inpatients and outpatients.

Conclusions: PEECE was found to be a feasible instrument for use with inpatient and outpatients, being easily understood and completed. Further psychometric testing is recommended.

The Patient Evaluation of Emotional Comfort Experienced (PEECE) is a 12-item questionnaire which measures the mental well-being state of emotional comfort. This paper describes the development and testing of this new research instrument which is intended for use with inpatients and outpatients within the acute care hospital setting.

\section{BACKGROUND}

There has been an increased awareness in recent years regarding patient experience

\section{Strengths and limitations of this study}

- This is the first publication of a new research instrument to measure the mental well-being state of emotional comfort.

- This instrument will contribute to the awareness, understanding and measurement of patient experience and outcomes.

- It will assist with development and increased use of psychosocial interventions and may be used to identify patients in additional need of psychosocial care.

- This work represents a change in focus for evaluating positive rather than negative health outcomes and advocates greater use of a biopsychosocial healthcare model.

- The reliability and validity of the instrument are limited to the results of this study. Further psychometric testing in different populations and settings is recommended.

and psychological well-being. Increasing public criticism and media attention regarding this has put pressure on healthcare organisations to revisit psychosocial aspects of patient care. ${ }^{1}$ The biopsychosocial approach to healthcare, first outlined in 1977 by Engel, challenged the biomedical model and proposed that psychosocial factors significantly impacted on physical illness experiences. ${ }^{2}$ However, despite increasing evidence regarding the therapeutic effect of a biopsychosocial approach, ${ }^{2}{ }^{3}$ the biomedical model predominates healthcare delivery internationally. $^{45}$

The biomedical model leaves little room for psychosocial interventions ${ }^{6} 7$ and healthpromoting activities. ${ }^{8}$ In 1992, nurses internationally were invited to use and evaluate nursing knowledge and theories in their clinical practice rather than continuing to apply the biomedical model. ${ }^{9}$ This has occurred in different settings with varying degrees of 
success. ${ }^{10}$ 'Person centredness' has been promoted, where care is individualised and holistic. ${ }^{11}$ However, unfavourable work environments limit the degree to which staff are able to provide this type of care to all patients. ${ }^{12}$ This creates a challenging juxtaposition for nurses. ${ }^{6}{ }^{13}$ For the patient, deficits in psychosocial care may jeopardise their overall sense of well-being and comfort, and impact on their ability to heal and participate in health-promoting activities. ${ }^{14}$

Our understanding of health psychology has increased in recent years and evidence relating to the influence of multiple psychosocial factors on healing has been found. This includes the effect of positive clinicianpatient communication ${ }^{15}$ as well as patient participation and engagement in care. ${ }^{16}{ }^{17}$ A systematic review of 55 studies revealed a positive association between patient experience, clinical safety and effectiveness, and it has been suggested that patient experience should be assessed routinely as a measure of quality. ${ }^{18}$ Numerous instruments have been developed to measure patient satisfaction with healthcare; however, there is recognition that measurement of patient experiences of humanity of care is more sensitive and useful. ${ }^{19}$

It has been suggested that a paradigm shift in healthcare is required which recognises and incorporates patient views and perspectives, ${ }^{20}$ although more research is required to further determine the relationship of these factors to patient outcomes. ${ }^{15}$ The PEECE instrument measures the patient experience outcome of emotional comfort and it is suggested that this instrument may be used to explore the effect of various psychosocial interventions in different healthcare populations.

\section{Comfort and hospitalised patients}

There has been little consensus over the years in terms of definitions of comfort, yet it is recognised as a basic human need which must be met before the process of healing is addressed. ${ }^{21}$ Comfort is an outcome which is commonly referred to in the care of hospitalised patients. The role of comfort in hospitals has been traced back to 1900 with nurses having an active role in its promotion. ${ }^{22}$ In 1994, Kolcaba ${ }^{23}$ developed a theory of holistic comfort for nursing based on concept analysis and work on this theory has continued until now. In Kolcaba's theory, comfort was viewed as a positive outcome which encompassed physical, psychospiritual, social and environmental dimensions. ${ }^{24}$ Comfort was defined as "an immediate state of being strengthened..." (p.47). Three types of comfort were identified, such as relief, ease and transcendence. Transcendence relates to performance and is a desirable outcome because it leads to increased health-seeking behaviours. ${ }^{25}$

In previous qualitative research by the first author (AMW), a substantive theory about the psychosocial experience of the patient was developed. ${ }^{14} 26$ 'Emotional comfort' was identified in that theory as a therapeutic state which assisted patients to be proactive in their recovery. Emotional comfort can be viewed as an outcome of patient experience and refers to a perceived personal psychological status. Emotional comfort is defined as pleasant positive feelings, a state of relaxation, an optimistic approach to life, where a person feels happy and their mood is high in spirits. Emotional comfort is associated with less physical discomfort.

Patients' feelings of personal control are a central feature of emotional comfort. Personal control refers to the patient's ability to influence, either externally or internally, the level of comfort associated with situations or environments encountered during hospitalisation. ${ }^{14}$ The interpersonal interactions experienced by patients, ${ }^{27}$ factors within the environment, ${ }^{28}$ as well as personal characteristics of the patient, ${ }^{29}$ all impact on emotional comfort. Patients' feelings of security, knowing, value as a person and connection to others, all influence the level of emotional comfort experienced. Patients who feel emotionally comfortable are more likely to participate in recovery promoting activities and feel a greater sense of empowerment, enablement and engagement (see figure 1). ${ }^{30}$

\section{Related measurement instruments}

In 2008, an instrument (questionnaire) was developed by the first author, using data from the original study. This instrument measured the emotional care experienced by patients in hospital through interpersonal interaction with staff. The reliability and validity of the 'Patient Evaluation of Emotional Care experienced during Hospitalisation' (PEECH) was established. ${ }^{29} 30$ The PEECH was further developed by Murrells $e t a{ }^{31}$ used in combination with the Picker Patient Experience Questionnaire to measure relational aspects of hospital care in England.

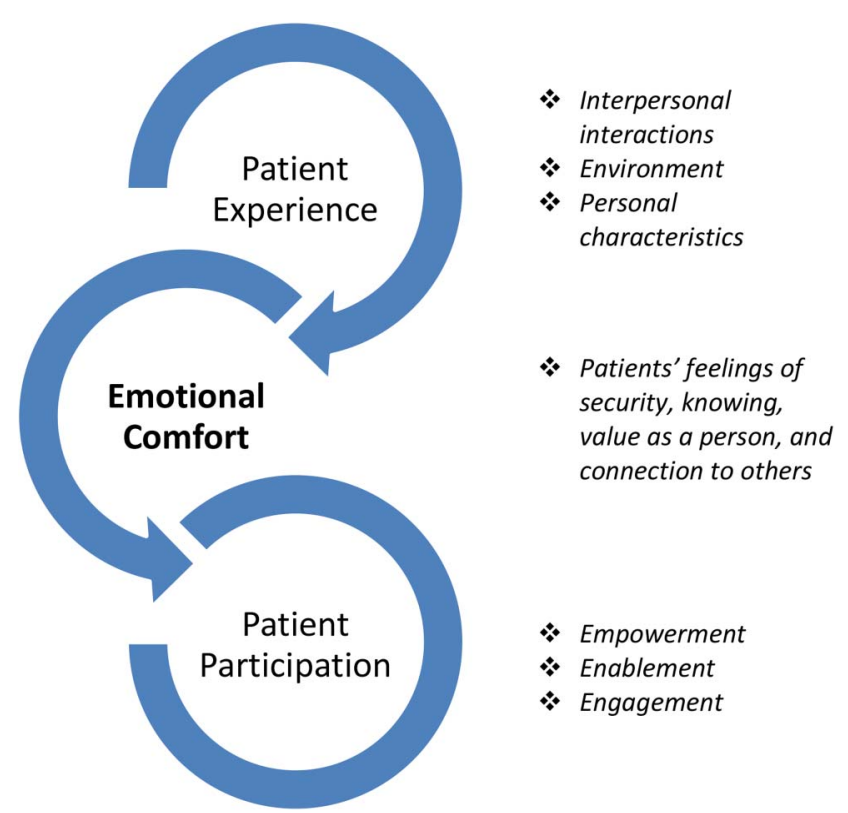

Figure 1 Emotional comfort in relation to patient experience and participation. 
Further work on the concept of emotional comfort was undertaken through a qualitative study of 16 patients attending a cancer support centre offering complementary therapies in a hospital setting. ${ }^{7}$ Perspectives of therapeutic and non-therapeutic experiences of integrative therapy of patients with cancer were explored. The findings indicated that the personal control of participants was increased by their attendance at the cancer support centre and this helped to facilitate feelings of emotional comfort. When patients felt emotionally comfortable, they were found to be more actively involved in the treatment of their illness. The centre was described as an 'Oasis' in the hospital, a special place where patients felt safe, valued and cared for as a whole person. The centre also provided a sense of community, a place where people could connect, especially patients who were living away from home. The use of complementary therapies were highly valued and said to evoke feelings of relaxation and calm. Through this work, it was recognised that there could also be value in the measurement of emotional comfort itself, to capture the influence of other factors apart from interpersonal interactions, and hence the work described in this paper.

The state of emotional comfort could be considered as a state of subjective psychological well-being. Several instruments have been developed to measure these concepts such as the 'the Psychological General Well-being Index', ${ }^{32}$ the 'Scales of Psychological Well-being' ${ }^{33}$ and 'the Everyday Feeling Questionnaire'. ${ }^{34}$ Although these instruments have merit, none are specifically designed for use in patient populations. An instrument, developed through an in-depth analysis of the positive state of comfort, from the perspective of ill persons, is more likely to be sensitive to any changes which result from psychosocial interventions implemented by healthcare providers. Development of an instrument with an ill population will ensure ease of completion by patients and administration by healthcare providers.

Only two previous instruments measuring the comfort of patients have previously been developed, the General Comfort Questionnaire ${ }^{35}$ and the Radiation Therapy Comfort Questionnaire. ${ }^{25}$ However, these instruments differ from PEECE as they measure holistic comfort and include physical, psychospiritual, social and environmental dimensions.

\section{Objectives}

This paper describes the development and testing of an instrument to measure the emotional comfort of patients. There were four objectives:

- To determine if emotional comfort is a uniquely identifiable concept that can be measured.

- To establish whether the new instrument demonstrates face and content validity.

- To explore the feasibility of the instrument by examining whether it is clear and easily understood by patients.
- To determine whether the instrument demonstrates internal consistency reliability.

\section{METHODS}

An instrument to measure emotional comfort was developed and tested in a hospital setting using four steps:

\section{Construction of the instrument}

In step 1, PEECE was constructed using the raw data and analysis from the previous qualitative work on emotional comfort. ${ }^{26}$ Relevant published literature and previously published instruments were also reviewed and used in the construction of the instrument. The study received ethical approval from the Human Research Ethics Committee at a public hospital and University in Perth, Western Australia. Informed consent was obtained from all individual participants included in this study.

\section{Assessment of face and content validity}

In step 2, an expert panel of eight persons was convened to assess the face and content validity of the PEECE instrument. This panel was multidisciplinary and consisted of representatives from relevant areas of nursing, medicine and clinical psychology. The panel included both clinicians and researchers.

The initial instrument consisted of 15 questions relating to emotional comfort and 7 demographic items. Each panel member was provided with the original publication which defined emotional comfort ${ }^{14}$ and asked to read this prior to reviewing the instrument. Panel members were asked to state 'yes' or 'no' to the individual emotional comfort questions in terms of the following: 'wording is clear', 'fits with emotional comfort', 'measures emotional comfort' and 'question is needed'. A space for comments for each question was provided and members were also asked to review the demographic questions.

\section{Testing for clarity and feasibility for use with patients}

In step 3, the PEECE instrument was pilot tested using a sample of 57 outpatients. These patients were identified through a cancer support centre, as well as a haematology and cardiac rehabilitation clinic at a public hospital located in Perth, Western Australia. Patients were eligible to participate if they were aged over 18 years, able to communicate in English and consented to participate. The instrument was administered by a research assistant and feedback regarding the understanding of the phrasing of the questions and the ability of patients to answer was also explored. Data collection took place in 20132014.

The European Organisation for Research and Treatment of Cancer feedback form ${ }^{36}$ was used as a further evaluation of the PEECE instrument for length, clarity and presence of distressing questions. Patients completed the form after completing the PEECE instrument. They were asked to identify which questions, if 
any, they found difficult to answer, and if any of the questions had concerned or upset them. Space was provided for comments in addition to the questions about the instrument.

\section{Assessment of reliability, construct validity of the tool and} assessment of the internal structure

A sample of 317 patients was recruited in the main study during 2014 at the same acute care hospital as the pilot study. The selection criteria were the same as in step 3, but the population consisted mainly of inpatients (excluding the emergency department and the intensive care unit) along with some outpatients. The clinical nurse specialist for each clinical area was contacted by the research assistant and asked to identify potential participants who were deemed well enough to participate. Patients were approached and informed of the study. If the patient was willing to participate, a consent form was signed.

An exploratory factor analysis (using SPSS V.22) using principal axis factor analysis was first used to determine the underlying dimensions of the PEECE instrument. A confirmatory factor analysis (using Mplus V.6.0) was then used to test the goodness of fit of the hypothesised factors structures. For the pilot study, a separate factor analysis was performed on each of the subscales to verify the internal structure of the PEECE using principal components with varimax rotation. Cronbach's $\alpha$ was used to determine the reliability.

Participants in the main study were given an identical second questionnaire to complete 7 days following completion of the first questionnaire, together with a reply paid envelope. This was done to examine the stability of the PEECE instrument over time and within the hospital setting (test-retest). Two hundred and three participants returned this questionnaire. The $\kappa$ was used for testretest reliability of the ordinal items.

Written comments from participants on the questionnaires were transferred to a word document and coded using the qualitative data management program NVivo (QSR International, V.10, 2014). Content analysis was performed using these data.

\section{RESULTS}

\section{Face and content validity of PEECE}

Following construction of a 15-item instrument, the face and content validity was assessed using a multidisciplinary expert panel. The responses from this panel were collated and the instrument was adjusted and reduced to 12 questions relating to emotional comfort. No changes to the demographic questions were indicated. The instrument was named PEECE.

\section{Clarity and feasibility: pilot study}

Fifty-seven patients participated in the pilot study using the new instrument. The average age of the patients in the sample was 60.6 (SD 10.5) with 54\% male and $46 \%$ female. The majority of patients were born in Australia $(61 \%), 14 \%$ from the UK, $11 \%$ from New Zealand and the remaining $14 \%$ from a wide range of backgrounds. Over one-third of patients had been hospitalised once in the past year $(36 \%), 23 \%$ were hospitalised twice in the past year, 25\% hospitalised at least three times in the past year and $16 \%$ were not hospitalised in the past year. Health conditions included diagnosis of either cancer $(58 \%)$ or a cardiac problem $(42 \%)$.

\section{Participant feedback: pilot study}

The majority of patients took $<10 \mathrm{~min}$ to complete the questionnaire $(61 \%)$, while $19 \%$ took $11-15 \mathrm{~min}, 14 \%$ took $16-20 \mathrm{~min}, 4 \%$ took $21-30 \mathrm{~min}$ and $2 \%$ took over 30 min. Overall, 25\% ( $n=13)$ of patients had help completing the questionnaire. Help was given by a family member $(n=4)$, friend $(n=1)$, community nurse $(n=1)$ and research assistant $(n=7)$. Help included verbal support $(n=3)$, making sure questions were understood $(n=4)$, filling out the form $(n=1)$, and dates and spelling $(\mathrm{n}=1)$.

Following a thorough review of the pilot results, it was decided that no changes to the instrument were indicated. The data from the pilot study were therefore included in the analysis for the main study.

\section{Reliability, construct validity and assessment of internal structure: pilot study}

PEECE consists of 12 items, all of which start with the same statement "I feel...relaxed, valued, safe, calm, cared for, at ease, like smiling, energised, content, in control, informed, thankful". Participants were asked to score how they were feeling emotionally 'right now' and to tick a box corresponding to five possible responses from 'not at all', 'very little', 'somewhat', 'very' and 'extremely' for each of the 12 items. The scores were converted into numbers from 0 (not at all) to 4 (extremely).

An exploratory factor analysis using principal axis factor analysis was used first to determine underlying themes within the data. Final estimates of communalities were iterated from squared multiple item correlations to convergence. The item pool was deemed suitable for factor analysis (Kaiser-Meyer-Olkin $(\mathrm{KMO})=0.78)$. Using Kaiser's criterion (Eigenvalues $\geq 1.0$ ) together with Cattell's scree test, three factors were extracted accounting for $67 \%$ of the common variance in the questionnaire data. A confirmatory factor analysis was then used and overall adequate fit was obtained where both the Comparative Fit Index (CFI) and the Tucker-Lewis Index $(\mathrm{TLI})$ were $>0.9(\mathrm{CFI} \geq 0.9 \text {, TLI } \geq 0.9)^{37}$ with excellent scale reliability (ie, how accurate and precise is the instrument; all $\alpha>0.7$; table 1). Factor loadings ranged from 0.49 to 0.85 . Cronbach's $\alpha$ was used to determine the reliability of the three factors. All factors had high significant reliability with Cronbach's $\alpha$ coefficient ranging from 0.74 to 0.88 . 
Table 1 Factors with items ranked in order of factor loadings: pilot study

\begin{tabular}{lll}
\hline Factor & Item & Factor loading \\
\hline Factor 1 & Q2 Valued & 0.846 \\
& Q5 Cared for & 0.827 \\
& Q3 Safe & 0.697 \\
& Q7 Smiling & 0.582 \\
& Q12 Thankful & 0.580 \\
Factor 2 & Q11 Informed & 0.493 \\
& Q6 At ease & 0.821 \\
Factor 3 & Q4 Calm & 0.775 \\
& Q1 Relaxed & 0.755 \\
& Q10 In control & 0.736 \\
& Q8 Energised & 0.676 \\
& Q9 Content & 0.518 \\
\hline
\end{tabular}

Reliability, construct validity and assessment of internal structure: main study

The total sample for the main study was 374 which included data from the 57 participants in the pilot study, as no changes to the instrument were required. The average age of patients in the sample was 60.7 (SD 16.3) with $49.5 \%(n=185)$ of male patients and $50.5 \% \quad(n=189)$ of female patients. The majority of patients were born in Australia $(61 \%)$ with a further $19 \%$ from the UK and $4 \%$ from New Zealand, while the remaining $16 \%$ were from a range of backgrounds. Over one-third of patients had been hospitalised once in the past year (37\%), $23 \%$ were hospitalised twice in the past year, $15 \%$ were hospitalised three times in the past year, and $4 \%$ were not hospitalised in the past year. The rest of the sample $(21 \%)$ were hospitalised four or more times. Health conditions included cancer $(23 \%)$, gastrointestinal $(18 \%)$, respiratory $(16 \%)$, haematological cancer $(10 \%)$, cardiac $(7 \%)$, renal $(7 \%)$, orthopaedic $(4 \%)$, complications from treatment $(3 \%)$, endocrinology $(1.3 \%)$, dermatology $(1.3 \%)$, neurology $(1.6 \%)$, other $(7.2 \%)$ and more than one health problem $(2 \%)$. The majority of patients recruited for the main study were inpatients $(83 \%)$.

\section{Factor analysis: main study}

The analysis for the main study followed the same methodology as for the pilot study using an exploratory factor analysis using principal axis factor analysis, followed by a principal component analysis. Two factors were extracted using an exploratory factor analysis accounting for $58 \%$ of the common variance factor.

A confirmatory factor analysis was then used to test the goodness of fit of the two factor structures. An overall adequate fit was obtained where both the CFI and the TLI were $>0.9$. Factor loadings ranged from 0.63 to 0.86 . Loadings of 0.50 and over are considered "practically significant'. ${ }^{38}$ The PEECE instrument was found to contain two subscales. Factor 1 was named 'positive emotions' and factor 2 'perceived meaning' (see table 2 for factor loadings).

\section{Factor 1: positive emotions}

Sixty-nine per cent $(n=258)$ of patients fell into the high level of positive emotions and $31 \%(n=116)$ of patients fell into the low level of positive emotions. The $\chi^{2}$ analysis was used to determine if there were any significant dependencies between demographic variables and positive emotions.

There were no significant differences between the levels of positive emotions with respect to age, country of birth, main health condition or the number of times hospitalised in the past year (all $\mathrm{p}>0.05$ ). There were, however, significant differences with respect to gender with a significantly greater proportion of men $(74 \%)$ in the high level of positive emotions compared with women $(64 \% ; \mathrm{p}<0.05)$. Binary logistic regressions were used to calculate ORs. Men were 1.6 times more likely to have high levels of positive emotions than women $(\mathrm{OR}=1.60,95 \%$ CI 1.03 to 2.50; table 3$)$.

\section{Factor 2: perceived meaning}

Ninety-four per cent $(n=353)$ of patients fell into the high level of perceived meaning category and 6\% $(n=21)$ of patients fell into the low level of perceived

Table 2 Subscales with item analysis ranked in order of factor loadings: main study

\begin{tabular}{llllrll}
\hline Subscale & Item & Factor loading & Skewness & Kurtosis & $\begin{array}{l}\text { Corrected item-total } \\
\text { correlation }\end{array}$ & $\begin{array}{c}\text { Cronbach's } \boldsymbol{\alpha} \\
\text { if item deleted }\end{array}$ \\
\hline Positive emotions & Q4 Calm & 0.858 & -0.600 & 0.276 & 0.732 & 0.847 \\
& Q6 At ease & 0.802 & -0.557 & 0.267 & 0.707 & 0.850 \\
& Q9 Content & 0.792 & -0.458 & -0.135 & 0.700 & 0.850 \\
& Q1 Relaxed & 0.789 & -0.531 & 0.608 & 0.668 & 0.856 \\
& Q10 In control & 0.714 & -0.293 & -0.720 & 0.625 & 0.862 \\
Perceived meaning & Q7 Smiling & 0.684 & -0.402 & -0.305 & 0.563 & 0.869 \\
& Q8 Energised & 0.674 & 0.063 & -0.342 & 0.616 & 0.862 \\
& Q5 Cared for & 0.816 & -1.025 & 1.546 & 0.666 & 0.745 \\
& Q2 Valued & 0.770 & -0.672 & 0.656 & 0.643 & 0.748 \\
& Q11 Informed & 0.728 & -0.652 & -0.032 & 0.591 & 0.767 \\
& Q3 Safe & 0.677 & -1.101 & 1.473 & 0.534 & 0.781 \\
& Q12 Thankful & 0.628 & -1.381 & 2.214 & 0.524 & 0.786 \\
\hline
\end{tabular}


Table 3 Proportion of patients in low and high levels of positive emotions and perceived meaning by demographics

\begin{tabular}{|c|c|c|c|c|c|c|c|c|}
\hline \multirow[b]{2}{*}{ Demographics } & \multicolumn{4}{|c|}{ Positive emotions } & \multicolumn{4}{|c|}{ Perceived meaning } \\
\hline & $\begin{array}{l}\text { Low } \\
\text { (\%) }\end{array}$ & $\begin{array}{l}\text { High } \\
(\%)\end{array}$ & $\frac{\chi^{2}}{\chi^{2}}$ & p Value & $\begin{array}{l}\text { Low } \\
\text { (\%) }\end{array}$ & $\begin{array}{l}\text { High } \\
\text { (\%) }\end{array}$ & $\frac{\chi^{2}}{\chi^{2}}$ & p Value \\
\hline Gender & & & 4.398 & $0.036^{*}$ & & & 2.316 & 0.128 \\
\hline Male & 25.9 & 74.1 & & & 3.8 & 96.2 & & \\
\hline Female & 36.0 & 64.0 & & & 7.4 & 92.6 & & \\
\hline Age & & & 5.974 & 0.113 & & & - & - \\
\hline $18-50$ & 30.1 & 69.9 & & & 6.0 & 94.0 & & \\
\hline $51-59$ & 42.5 & 57.5 & & & 6.8 & 93.2 & & \\
\hline $60-69$ & 26.0 & 74.0 & & & 2.9 & 97.1 & & \\
\hline $70+$ & 28.9 & 71.1 & & & 7.0 & 93.0 & & \\
\hline Country of birth & & & 0.018 & 0.892 & & & 2.239 & 0.135 \\
\hline Australia & 31.3 & 68.7 & & & 7.0 & 93.0 & & \\
\hline Other & 30.6 & 69.4 & & & 3.4 & 96.6 & & \\
\hline Main health conditions & & & 4.770 & 0.189 & & & - & - \\
\hline Cancer & 25.0 & 75.0 & & & 3.6 & 96.4 & & \\
\hline Gastro & 35.8 & 64.2 & & & 7.5 & 92.5 & & \\
\hline Respiratory & 40.0 & 60.0 & & & 3.3 & 96.7 & & \\
\hline Other & 28.8 & 71.2 & & & 6.7 & 93.3 & & \\
\hline Number of times hospitalised in past year & & & 1.123 & 0.772 & & & - & - \\
\hline 0 & 35.7 & 64.3 & & & 7.1 & 92.9 & & \\
\hline 1 & 31.4 & 68.6 & & & 5.1 & 94.9 & & \\
\hline 2 & 34.5 & 65.5 & & & 4.8 & 95.2 & & \\
\hline $3+$ & 28.3 & 71.7 & & & 6.5 & 93.5 & & \\
\hline
\end{tabular}

meaning. The $\chi^{2}$ analysis was used to determine if there were any significant dependencies between demographic variables and perceived meaning. There were no significant differences with respect to the levels of perceived meaning and gender and country of birth (all $\mathrm{p}>0.05$; table 3 ). Owing to the large proportions of people in high levels of perceived meaning, $\chi^{2}$ statistics could not be calculated for age, main health condition or the number of times hospitalised in a year.

\section{Reliability: main study}

Using the Kolmogorov-Smirnov test, all scale items were significantly different from normal (all $\mathrm{p}>0.05$; table 2). However, when examining the skewness and kurtosis of items, all items except 'thankful' fell within the range of -2 to +2 and are considered to be normally distributed. ${ }^{39}$ Cronbach's $\alpha$ was used to determine the reliability of the two subscales. Scale reliability was found to be excellent (positive emotions $\alpha=0.80$, perceived meaning $\alpha=0.87$ ). Carmines and Zeller ${ }^{40}$ suggested that at least $50 \%$ of item-to-total correlations should be between 0.40 and 0.70 . Scores above 0.70 could suggest redundancy of items while scores below 0.40 indicate that the item may not contribute information. All items showed high discrimination (corrected item-to-total correlation $>0.20$ ). While all item-to-total correlations were within the 0.40 0.70 bounds for perceived meaning ( 0.40 to 0.67$), 86 \%$ of positive emotions item-to-total correlations $(0.56$ to 0.73 ) were within the bounds, which is higher than the suggested $50 \%$. Since removing any of the items from the subscales would decrease Cronbach's $\alpha$, all items were kept in the subscales.

\section{Test-retest}

Data were analysed from 203 participants who had completed two questionnaires on separate occasions, to examine the stability of the PEECE instrument over time. The $\kappa$ has been used for test-retest reliability of the ordinal items (table 4). All items showed significant test-retest agreement (all $\mathrm{p}<0.05)$.

\section{Participant feedback main study}

Comments from participants written on the questionnaires were coded into six main categories: staff influences, provision of service, current level of health or illness, hospital food, communication and emotional well-being.

Staff influences related to the care received from all staff in the hospital. Most of the comments were very positive and included terms such as 'outstanding', 'brilliant', 'supportive', 'friendly', 'helpful', 'diligent', 'attentive' and 'top class'. Nurses were described specifically as 'caring', 'compassionate', 'dedicated' and 'exceptional'; medical staff were described as 'lifesavers'. Comments about provision of service were mixed with some patients feeling frustrated about delays in treatment, diagnostic mistakes, inadequate nurse staffing numbers and communication issues. Current level of health or illness related to perceived control over circumstances and coping with treatment outcomes. For example, pre-existing anxiety 
Table 4 Test-retest reliability

\begin{tabular}{llr}
\hline & к & p Value \\
\hline Q1 Relaxed & 0.111 & 0.011 \\
Q2 Valued & 0.261 & $<0.001$ \\
Q3 Safe & 0.183 & $<0.001$ \\
Q4 Calm & 0.199 & $<0.001$ \\
Q5 Cared for & 0.189 & $<0.001$ \\
Q6 At ease & 0.247 & $<0.001$ \\
Q7 Smiling & 0.232 & $<0.001$ \\
Q8 Energised & 0.193 & $<0.001$ \\
Q9 Content & 0.220 & $<0.001$ \\
Q10 In control & 0.096 & $<0.001$ \\
Q11 Informed & 0.145 & $<0.001$ \\
Q12 Thankful & 0.334 & $<0.001$ \\
\hline
\end{tabular}

or depression, the experience of stoma surgery, or receiving chemotherapy restricted their ability to carry out regular daily activities. Some patients found the hospital food 'excellent', while others felt that the food was 'substandard'. Communication comments also varied with some patients feeling that they had all their questions answered, and others either not understanding the information they were given, or feeling that they had not being given enough information. In the emotional well-being category, participants described being stressed and needing more emotional support. Anger about not having enough control over their condition was also expressed. Some patients felt that the hospital environment was depressing and uncomfortable when they had to share rooms with other sick or confused patients. Others felt that they had a positive outlook or state of mind, regardless of their circumstance, and that they were well supported by staff and family.

\section{DISCUSSION}

The PEECE research instrument was developed using previous qualitative work on the emotional comfort of hospitalised patients together with relevant published literature. The psychometric properties of this instrument were explored in a sample of 374 patients experiencing various health problems. Emotional comfort was found to be a uniquely identifiable concept that could be measured, with face and content validity of the instrument established using an expert panel. The clarity and feasibility of the instrument was assessed by 57 patients in the pilot study. It was easily understood and completed in a short period of time. Highly significant internal consistency reliability was demonstrated with Cronbach's $\alpha$ coefficient ranging from 0.74 to 0.88 .

Two factors were identified in the instrument and named positive emotions and perceived meaning. The characteristics of these factors are similar to those used in positive psychology, namely 'positive emotion' and 'meaning' described by Seligman ${ }^{41}$ in his book 'Flourish' (p.16-17). Seligman views these as elements of well-being and he also identifies 'engagement' and 'accomplishment' and 'positive relationships'. Fredrickson and Joiner's ${ }^{42}$ 'Broaden and build theory of positive emotions' highlights the potential long-term psychological benefits of positive emotions. The similarities between emotional comfort and well-being may assist in greater use of positive psychology principles in healthcare. Until now, the use of positive psychology has been limited and yet there is great potential for its application, particularly in the area of rehabilitation. ${ }^{43}$ PEECE provides a measure by which the effect of positive psychology interventions in patient populations could be evaluated.

Our understanding of what contributes to well-being and perceptions of happiness have increased in recent years and the health benefits have been researched. A meta-analysis of 150 studies found evidence to suggest that there is a relationship between physical well-being and positive health status. ${ }^{44}$ Likewise, a relationship between mental well-being and positive thoughts has also been identified. ${ }^{45}$ Measurement of these aspects of well-being using the PEECE instrument may prove to be valuable indicators of future healthcare needs and outcomes.

In terms of the factor positive emotions, it was found that there were a greater proportion of male patients reporting higher levels of positive emotions than female patients. This is not a surprising finding, since differences exist in socialisation between men and women, the effect of this on coping strategies used and illness perceptions have been previously noted. ${ }^{46}$ Research has revealed significant gender differences in coping strategies used by cancer survivors ${ }^{47}$ and persons with musculoskeletal pain. ${ }^{48} \mathrm{~A}$ meta-analysis of 300 studies of well-being in old age found men to have higher levels of life satisfaction, happiness and self-esteem than women. ${ }^{49}$

Patients in this study described a number of aspects of the hospital environment which impacted on their emotional comfort. A greater awareness, understanding and measurement of the effect of factors in the environment on the well-being of the patient will ultimately lead to improvements in patient experiences and outcomes.

\section{CONCLUSIONS}

In conclusion, this study describes the first use of a new research instrument measuring the emotional comfort of patients. The PEECE instrument was found to be a feasible instrument for use with inpatient and outpatients, being easily understood and completed. This instrument represents a change in focus for evaluating positive rather than negative health outcomes. It is predicted that an assessment of patients' feelings of emotional comfort is more likely to indicate whether interventions of a psychosocial nature are of value.

It is anticipated that PEECE may be useful in clinical practice as a means by which vulnerable patients may be identified. PEECE provides a standard measure by which patients could be monitored and interventions adjusted 
accordingly. It has particular application for inpatients and outpatients, patients with chronic illness or longterm rehabilitation. There may also be application for this instrument in other areas such as mental health.

Evidence of face and content validity was demonstrated as well as internal consistency reliability. The reliability and validity of the instrument are limited to the results of this study. Subsequent work on this instrument could explore the concurrent validity. Combination with other instruments which address similar concepts would also be useful, such as the Patient Activation Measure, ${ }^{50}$ the Partners in Health Scale, ${ }^{51}$ the Patient Enablement Instrument, ${ }^{52}$ the Patient Health Engagement Scale ${ }^{16}$ and the Altarum Consumer Engagement Measure. ${ }^{53}$ Further psychometric testing in different populations and settings is recommended.

\section{Author affiliations}

${ }^{1}$ School of Health Professions, Murdoch University, Murdoch, Western Australia, Australia

${ }^{2}$ Centre for Nursing Research, Sir Charles Gairdner Hospital, Nedlands, Western Australia, Australia

${ }^{3}$ Health Promotion Evaluation Unit, School of Sport Science, Exercise and Health, The University of Western Australia, Crawley, Western Australia, Australia

${ }^{4}$ School of Nursing and Midwifery, Institute of Health Research, The University of Notre Dame Australia, Fremantle, Western Australia, Australia ${ }^{5}$ SolarisCare Foundation, Sir Charles Gairdner Hospital, Nedlands, Western Australia, Australia

${ }^{6}$ School of Psychiatry and Clinical Neurosciences, The University of Western Australia, Crawley, Western Australia, Australia

${ }^{7}$ University of Technology Sydney, Ultimo, New South Wales, Australia

${ }^{8}$ Department of Haematology, Sir Charles Gairdner Hospital, The University of Western Australia, Crawley, Western Australia, Australia

\section{Twitter Follow Anne Williams @ProfAnneMW}

Acknowledgements Catherine Pienaar is acknowledged for the coordination and assistance with the pilot study and Dr Toni Musiello for contribution to the initial design and instrument development. The authors would also like to thank the following people for their assistance in the recruitment of patients for this study: David Jennings, Kylie McCullough, Gemma Evans, Claire Murphy-Marshall, Anne Matthews and Grace Chen.

Contributors All authors named on this paper have contributed significantly and are in agreement with the content of this manuscript. AMW, LL, CB, AP, $K B$, DJ were involved in conception of work. $E A, A M W$, $A P$ were involved in data collection. $\mathrm{LL}, \mathrm{AMW}, \mathrm{KB}, \mathrm{EA}$ were involved in data analysis and interpretation. AMW, $L L, C B, A P, K B, E A$ were involved in drafting the article. $A M W, L L, C B, A P, K B, E A$, DJ were involved in critical revision.

Funding SolarisCare Foundation grant. Proposal number G1000457; administered by Edith Cowan University.

Competing interests None declared.

Ethics approval Sir Charles Gairdner Hospital and Edith Cowan University.

Provenance and peer review Not commissioned; externally peer reviewed.

Data sharing statement No additional data are available.

Open Access This is an Open Access article distributed in accordance with the Creative Commons Attribution Non Commercial (CC BY-NC 4.0) license, which permits others to distribute, remix, adapt, build upon this work noncommercially, and license their derivative works on different terms, provided the original work is properly cited and the use is non-commercial. See: http:// creativecommons.org/licenses/by-nc/4.0/

\section{REFERENCES}

1. Day H. The meaning of compassion. Br J Nurs 2015;24:342-3.

2. Adler NE. Health disparities through a psychological lens. Am Psychol 2009;64:663-73.

3. Borrell-Carrio F, Suchman AL, Epstein RM. The biopsychosocial model 25 years later: principles, practice, and scientific inquiry. Ann Fam Med 2004;2:576-82.

4. Alonso $\mathrm{Y}$. The biopsychosocial model in medical research: the evolution of the health concept over the last two decades. Patient Educ Couns 2004;53:239-44.

5. Lane RD. Is it possible to bridge the biopsychosocial and biomedical models? Biopsychosoc Med 2014;8:3.

6. Dempsey C, Reilly B, Buhlman N. Improving the patient experience: real-world strategies for engaging nurses. J Nurs Adm 2014;44:142-51.

7. Williams AM, Bulsara CE, Joske DJL, et al. An oasis in the hospital: the perceived benefits of a cancer support center in a hospital setting offering complementary therapies. J Holist Nurs 2014;32:250-60.

8. Whitehead D. Health promoting hospitals: the role and function of nursing. J Clin Nurs 2005;14:20-7.

9. Parse RR. Nursing knowledge for the 21st century: an international commitment. Nurs Sci Q 1992:5:8-12.

10. Edwards KJ, Duff J, Walker K. What really matters? A multi-view perspective of one patient's hospital experience. Contemp Nurse 2014;49:122-36.

11. McCormack B, Karlsson B, Dewing J, et al. Exploring person-centredness: a qualitative meta-synthesis of four studies. Scand J Caring Sci 2010;24:620-34.

12. Maben J, Adams M, Peccei R, et al. 'Poppets and parcels': the links between staff experience of work and acutely ill older peoples' experience of hospital care. Int J Older People Nurs 2012;7:83-94.

13. Fackler CA, Chambers AN, Bourbonniere M. Hospital nurses' lived experience of power. J Nurs Scholarsh 2015;47:267-74.

14. Williams AM, Irurita VF. Emotional comfort: the patient's perspective of a therapeutic context. Int J Nurs Stud 2006;43:405-15.

15. Street RLJr, Makoul G, Arora NK, et al. How does communication heal? Pathways linking clinician-patient communication to health outcomes. Patient Educ Couns 2009;74:295-301.

16. Graffigna G, Barello S, Bonanomi A, et al. Measuring patient engagement: development and psychometric properties of the Patient Health Engagement (PHE) Scale. Front Psychol 2015;6:274.

17. Phillips NM, Street M, Haesler E. A systematic review of reliable and valid tools for the measurement of patient participation in healthcare. BMJ Qual Saf 2016;25:110-17.

18. Doyle $C$, Lennox L, Bell D. A systematic review of evidence on the links between patient experience and clinical safety and effectiveness. BMJ Open 2013;3:pii: e001570.

19. Black N, Jenkinson C. Measuring patients' experiences and outcomes. BMJ 2009;339:b2495.

20. Siriwardena AN, Gillam S. Patient perspectives on quality. Qual Prim Care 2014:22:11-15.

21. Malinowski A, Stamler LL. Comfort: exploration of the concept in nursing. J Adv Nurs 2002;39:599-606.

22. Mcllveen $\mathrm{KH}$, Morse $\mathrm{JM}$. The role of comfort in nursing care: 1900-1980. Clin Nurs Res 1995;4:127-48.

23. Kolcaba KY. A theory of holistic comfort for nursing. J Adv Nurs 1994;19:1178-84.

24. Kolcaba KY, Fisher EM. A holistic perspective on comfort care as an advance directive. Crit Care Nurs Q 1996;18:66-76.

25. Kolcaba K, Steiner R. Empirical evidence for the nature of holistic comfort. J Holist Nurs 2000;18:46-62.

26. Williams AM. The contribution of therapeutic interpersonal interactions to the comfort of hospitalised patients: a grounded theory study of the patient's perspective. Curtin University of Technology, 2003.

27. Williams AM, Irurita VF. Therapeutic and non-therapeutic interpersonal interactions: the patient's perspective. J Clin Nurs 2004;13:806-15.

28. Williams AM, Irurita VF. Enhancing the therapeutic potential of hospital environments by increasing the personal control and emotional comfort of hospitalized patients. Appl Nurs Res 2005;18:22-8.

29. Williams AM, Dawson SS, Kristjanson LJ. Translating theory into practice: using Action Research to introduce a coordinated approach to emotional care. Patient Educ Couns 2008;73:82-90.

30. Williams AM, Pienaar C, Toye $\mathrm{C}$, et al. Further psychometric testing of an instrument to measure emotional care in hospital. J Clin Nursing 2011:20:3472-82.

31. Murrells T, Robert G, Adams M, et al. Measuring relational aspects of hospital care in England with the 'Patient Evaluation of Emotional 
Care during Hospitalisation' (PEECH) survey questionnaire. BMJ Open 2013;3:pii: e002211.

32. Dupuy $\mathrm{H}$. The psychological well-being (PGWB) index. In: Wenger NK, Mattson ME, Furberg CD, Elinson J, eds. Assessment of quality of life in clinical trials of cardiovascular therapies. Le Jacq Publishing, 1984:170-84.

33. Ryff CD, Keyes CL. The structure of psychological well-being revisited. J Pers Soc Psychol 1995;69:719-27.

34. Uher R, Goodman R. The Everyday Feeling Questionnaire: the structure and validation of a measure of general psychological well-being and distress. Soc Psychiatry Psychiatr Epidemiol 2010;45:413-23.

35. Kolcaba K. Holistic comfort: Operationalizing the construct as a nurse-sensitive outcome. Adv Nurs Sci 1992;15:1-10.

36. Johnson C, Aaronson N, Blazeby JM, et al. Guidelines for developing questionnaire modules. 4th edn. EORTC Quality of Life Group, 2011.

37. Hu L, Bentler PM. Cutoff criteria for fit indexes in covariance structure analysis: conventional criteria versus new alternatives. Struct Equation Model 1999;6:1-55.

38. Hair JF, Black WC, Babin BJ, et al. Multivariate data analysis. 7th edn. New York: Pearson, 2010.

39. George D, Mallery M. SPSS for Windows Step by Step: a simple guide and reference, 17.0 update. 10th edn. Boston: Pearson, 2010.

40. Carmines E, Zeller R. Reliability and viability assessment. Thousand Oaks, CA: Sage publications, 1991

41. Seligman M. Flourish: a visionary new understanding of happiness and wellbeing. Atria Books, 2011.

42. Fredrickson $\mathrm{BL}$, Joiner T. Positive emotions trigger upward spirals toward emotional well-being. Psychol Sci 2002;13:172-5.

43. Kim JH, McMahon BT, Hawley C, et al. Psychosocial adaptation to chronic illness and disability: a virtue based model. J Occup Rehabil 2016;26:45-55.
44. Howell RT, Kern ML, Lyubomirsky S. Health benefits: meta-analytically determining the impact of well-being on objective health outcomes. Health Psychol Rev 2007;1:83-136.

45. Rice EL, Fredrickson BL. Of passions and positive spontaneous thoughts. Cogn Ther Res 2016. [Epub ahead of print].

46. Kelly MA, Sereika SM, Battista DR, et al. The relationship between beliefs about depression and coping strategies: gender differences. Br J Clin Psychol 2007;46:315-32.

47. Cho D, Park CL, Blank TO. Emotional approach coping: gender differences on psychological adjustment in young to middle-aged cancer survivors. Psychol Health 2013;28:874-94.

48. Grossi G, Soares JJF, Lundberg U. Gender differences in coping with musculoskeletal pain. Int J Behav Med 2000;7: 305-21.

49. Pinquart M, Sorensen S. Gender differences in self-concept and psychological well-being in old age: a meta-analysis. $J$ Gerentol 2001;56:195-213.

50. Hibbard JH, Stockard J, Mahoney ER, et al. Development of the Patient Activation Measure (PAM): conceptualizing and measuring activation in patients and consumers. Health Serv Res 2004;39(Part 1):1005-26.

51. Petkov J, Harvey P, Battersby M. The internal consistency and construct validity of the partners in health scale: validation of a patient rated chronic condition self-management measure. Qual Life Res 2010;19:1079-85.

52. Howie JG, Heaney DJ, Maxwell M, et al. A comparison of a Patient Enablement Instrument (PEI) against two established satisfaction scales as an outcome measure of primary care consultations. Fam Pract 1998;15:165-71.

53. Duke CC, Lynch WD, Smith B, et al. Validity of a new patient engagement measure: the Altarum Consumer Engagement (ACE) Measure. Patient 2015;8:559-68. 